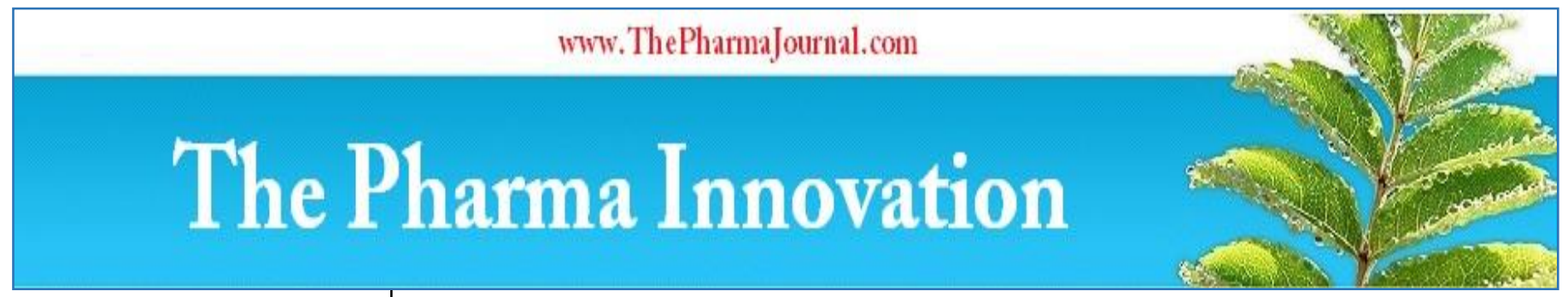

ISSN (E): 2277 - 7695

ISSN (P): 2349-8242

NAAS Rating: $\mathbf{5 . 0 3}$

TPI 2020; 9(6): 247-252

(C) 2020 TPI

www.thepharmajournal.com

Received: 12-04-2020

Accepted: 14-05-2020

Latika Yadav

Department of Food and Nutrition, Faculty of Home

Science, Bindheswari P.G.

College, Akbarpur, Uttar

Pradesh, India

Anchal Yadav

Department of Food and

Nutrition, Faculty of Home

Science, Bindheswari P.G.

College, Akbarpur, Uttar

Pradesh, India
Corresponding Author:

Latika Yadav

Department of Food and

Nutrition, Faculty of Home

Science, Bindheswari P.G.

College, Akbarpur, Uttar

Pradesh, India

\section{Standardization, development and organoleptic evaluation of food products prepared from gluten free flour mix}

\author{
Latika Yadav and Anchal Yadav
}

DOI: https://doi.org/10.22271/tpi.2020.v9.i6d.4776

Abstract

The present study was carried out with an aim of the development of Gluten Free Flour Mix food products for celiac disease/ gluten intolerance patients. Gluten Free Flour Mix was developed from the ragi, amaranth, buckwheat and fava bean flour. Gluten Free Flour Mix recipes were developed and standardized viz. biscuit, namakpara, papad, muffin and sev. These products were compared with the standard and evaluated for organoleptic evaluation. Overall acceptability of all products prepared from Gluten Free Flour Mix was more than compared to control. Calcium, Iron and Protein content was significantly higher in Gluten Free Flour Mix compared to control.

Keywords: Gluten free flour mix, gluten intolerance, organoleptic

\section{Introduction}

Celiac disease (CD) is a chronic systemic autoimmune disorder caused by permanent intolerance to gluten proteins in genetically susceptible individuals. Currently, celiac disease is tough to resemble multisystem immunological disorder rather than a disease restricted to the Gastro-Intestinal Tract (GIT) (Letizia et al. 2010) ${ }^{[1]}$. Celiac disease often called, gluten sensitivity enteropathy or non-tropical sprue is caused by a reaction of gliadin. The resulting damage to the villi of intestinal mucosa results in the potential or actual malabsorption of virtually all nutrients (Srilakshmi, 2014) ${ }^{[15]}$.

People suffering from celiac disease, wheat allergies, and wheat intolerance depend on glutenfree foods to maintain their quality of life (Brown, 2005) ${ }^{[2]}$. Celiac disease or gluten-sensitive enteropathy is a chronic disorder of the small intestine caused by exposure to gluten in the genetically predisposed individual (Hamer, 2005) ${ }^{[8]}$. When people with celiac disease eat food or use products containing gluten, their immune system reacts negatively by destroying the intestinal villi leading to the malabsorption of nutrients, thus adversely affecting the system of the body (Feighery, 1999) ${ }^{[5]}$. Gluten is a water-insoluble protein complex found in wheat, rye, and barley. A significant finding of celiac disease is villous atrophy of small intestine which leads to nutrient malabsorption and a broad range of clinical manifestations (Fansano et al. 2012) ${ }^{[4]}$.

In recent years, an increase in the diagnosed cases of the celiac disease, or allergic reaction/ intolerance to gluten consumed in food products, caused a growing interest in gluten-free products. A diet based on gluten-free products is characterized by a low content of some nutritional components such as proteins and mineral components like dietary fiber (Matgorzatu et al. 2008) ${ }^{[12]}$. A gluten-free diet is currently the only effective means of treating an individual with celiac disease. Such a diet enables celiac patients to control their symptoms and avoid various complications associated with this condition (Isabel et al. 2015) ${ }^{[10]}$. A gluten-free diet is expensive and difficult to maintain because of many products made from gluten-containing grains. Moreover, the contents of a gluten-free diet do not always ensure that an individual receives adequate nutrition (Alvarez et al. $2009^{[1]}$ and Segura and Rosell, 2011) [13]. While individuals on a gluten-free diet need to replace wheat, barley and rye and their derivatives with foods derived from naturally gluten-free cereal grains (e.g., rice, corn, buckwheat, sorghum, etc), but the recommended amounts of fiber, iron, and calcium can be more difficult to obtain to such a diet and good planning is required (Thompson et al. 2005) ${ }^{[16]}$. Population studies also indicate that a large proportion of celiac people remain undiagnosed; 
this is due to many clinicians being unfamiliar with the condition (Letizia et al. 2010) ${ }^{[11]}$.

A rapid change in the dietary lifestyle has been observed since few years along with urbanization, globalization and economic development leading to increase in the number of people suffering from poor health, which is reflected by the increased incidence of diseases such as obesity, diabetes, cardiovascular disease, stroke, hypertension and some type of cancer (Goyal et al. 2015) ${ }^{[6]}$. Celiac disease is a common health concern throughout the world, affecting approximately $1 \%$ of the population (Green, 2005) ${ }^{[7]}$. The gluten-free diet has benefits such as the recovery of the villi of the small intestine and reduced risk of malignant complications (Seraphin and Mobarhan, 2002) ${ }^{[14]}$. It is important to estimate the maximum gluten content that could be present in supposed gluten-free foods, even at a trace level. According to recent studies a limit of $20 \mathrm{mg} / \mathrm{kg}$ is admitted (Carols et al. 2014) ${ }^{[3]}$.

Celiac disease originally thought to occur only rarely in childhood is now recognized as a common condition that may be diagnosed at any age. Millets and legumes, which have a high nutritional value, were applied in the production of enriched gluten-free food products. Diet based on gluten-free products is often characterized by low contents of some nutritional components, as well as not- nutritional but physiologically important components like dietary fiber (Krupra et al. 2011) ${ }^{[9]}$. This is the reason; efforts are made to standardize and develop gluten-free flour mix products especially rich in protein, fiber, macro, and microelements, and their organoleptic evaluation.

\section{Materials and methods}

\subsection{Standardization of gluten free flour mix recipes}

In the present study recipes were standardized and developed by the use of Gluten Free Flour Mix. Gluten Free Flour Mix recipes prepared by different cooking methods. Recipes were standardized to achieve the desirable color, flavor, texture, taste, appearance and overall acceptability.

2.1.1. Namakpara Gluten Free Flour Mix (100 gm), ajwain seeds (2 gm), salt (according to taste) and oil (10 ml) were mixed properly. Knead hard dough with the help of warm water as required. It should be tighter than a chapatti dough. Make small balls of dough and rolled into medium sized chapatti with rolling pin. Cut the chapatti into small diamond shapes. Heat the oil in a frying pan then deep fried till golden brown and crispy.

2.1.2. Biscuit The butter (50gm) and sugar (50gm) were creamed together in a large bowl and creamed well until fluffy. Gluten Free Flour Mix (100gm), baking soda (1.5gm), baking powder $(1.5 \mathrm{gm})$ and chocolate powder $(20 \mathrm{gm})$ were sieved together and mix properly. Then slowly mixed dry ingredients into shortening cream and with the help of milk make soft dough. Rolled the dough and cut into desired shape with the help of cookie cutter. Preheat the oven at $180^{\circ} \mathrm{C}$ for 10 minutes. Bake the biscuits in oven at $180^{\circ} \mathrm{C}$ for $20-25$ minutes.

2.1.3. Muffin Preheat oven at $180^{\circ} \mathrm{C}$ for 10 minutes. Gluten Free Flour Mix (100gm), baking soda (1.5gm), baking powder $(1.5 \mathrm{gm})$ and chocolate powder $(20 \mathrm{gm})$ were sieved together and mix properly. The butter (50gm) and sugar (50gm) was creamed together in a large bowl and creamed well until fluffy. Then add dry ingredients and blend properly. Finally the carbonated beverages were added to the mixture and blended for 2 minutes to improve the quality of batter and final product. The batter was filled into the muffins moulds and baked at $180^{\circ} \mathrm{C}$ for $25-30$ minutes.

2.1.4. Sev All dry ingredients Gluten Free Flour Mix (100 $\mathrm{gm})$, turmeric powder (1gm), red chili powder (1gm) and salt (according to taste) mix in a large bowl. Add oil $(5 \mathrm{ml})$ in a mixture and mixed properly. Knead soft dough using water. For making the sev grease the sev mould press machine with little oil then put a dough ball in the sev mould. Heat oil in a pan. In the hot oil directly extrude the sev by sev press machine. Fried till golden brown and crisp.

2.1.5. Papad Add oil (5 ml), cumin seeds (5 gm), salt (according to taste) and red chili powder (2gm) in boiling water $(150 \mathrm{ml})$. Then add Gluten Free Flour Mix $(100 \mathrm{gm})$ in boiling water, stir continuously, mixed into the smooth dough, keep flame on low and cover with lid for 30 seconds. Remove from flame and cool it. Make soft dough, divide dough into small portion ( $10 \mathrm{~g}$ each ball). Then placed these dough balls in oiled plastic sheet and pressed each by rolling pin in round shape and size. After that papad were spread on a clean cloth for sun drying (2 days). Dried papad were deep fried in any oil or roast on flame.

\subsection{Sensory evaluation}

The prepared Gluten Free Flour Mix recipes were organoleptically evaluated by ten panels of judges. For the selection of panel members threshold test is used. The Gluten Free Flour Mix was evaluated for various sensory quality characteristics such as color, flavor, taste, texture, appearance, and overall acceptability.

Table 1: Score card for Organoleptic Evaluation

\begin{tabular}{|c|c|c|c|c|c|c|}
\hline \multicolumn{3}{|c|}{ Name of Panel member: } & \multicolumn{3}{|c|}{ Date: } \\
\hline $\begin{array}{c}\text { Code of } \\
\text { Sample }\end{array}$ & Color & Flavor & Texture & Appearance & Taste & $\begin{array}{c}\text { Overall } \\
\text { acceptability }\end{array}$ \\
\hline
\end{tabular}

Note: Fill score in columns according to your evaluation of given sample. Scoring is done on 9 point hedonic scale; scores are viz. Like extremely (9), Like very much (8), Like moderately (7), Like slightly (6), Neither like or dislike (5), Dislike slightly (4), Dislike moderately (3), Dislike very much (2), Dislike extremely (1) Evaluation of the product was done on the basis of 9 point hedonic scale. The test sample was given in triplicates with control. Control sample was prepared from the usual recipes. All samples were coded to avoid any type of biasness.

\subsection{Statistical Analysis}

Statistically, all the collected data on organoleptic evaluation were analyzed. Data were presented as mean \pm S.D. Analysis of Variance (ANOVA) was used to assess the sensory characteristics of Gluten Free Flour Mix recipes. Statistical analysis was performed using O.P. STAT Software.

\section{Results and discussion}

The present study was based on the standardization and development of gluten free flour mix recipes viz. Namakpara, Biscuit, Muffin, Sev and Papad. The developed products were tested for their organoleptic evaluation for the most acceptable level. The standardized and developed Gluten Free Flour Mix Products are given in Plate 3.1 under sub heading.

3.1 Plates: Standardization and development of Raw wheat Flour (RWF) Gluten Free Flour Mix (GFFM) Products 


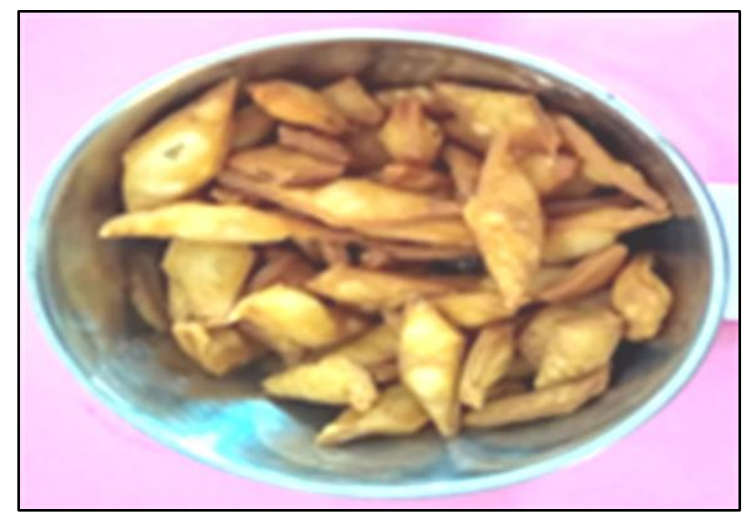

Plate 1(a): Namakpara prepared from RWF

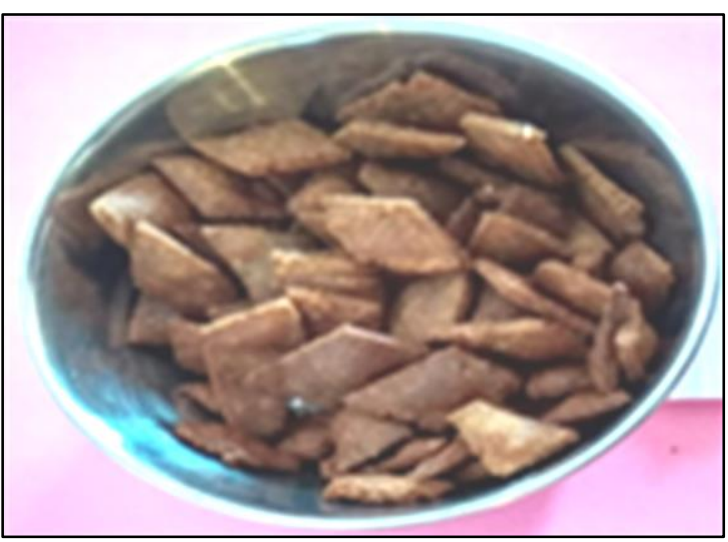

Plate 1(b): Namakpara prepared from GFFM

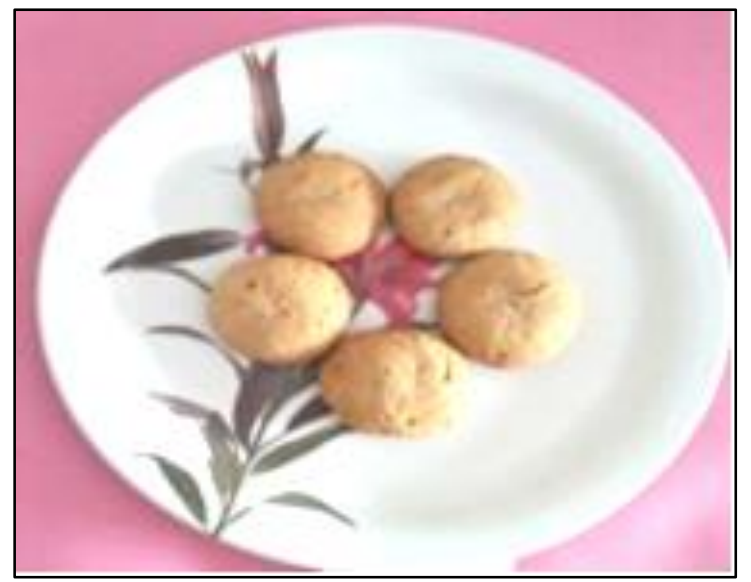

Plate 2(a): Biscuit prepared from RWF

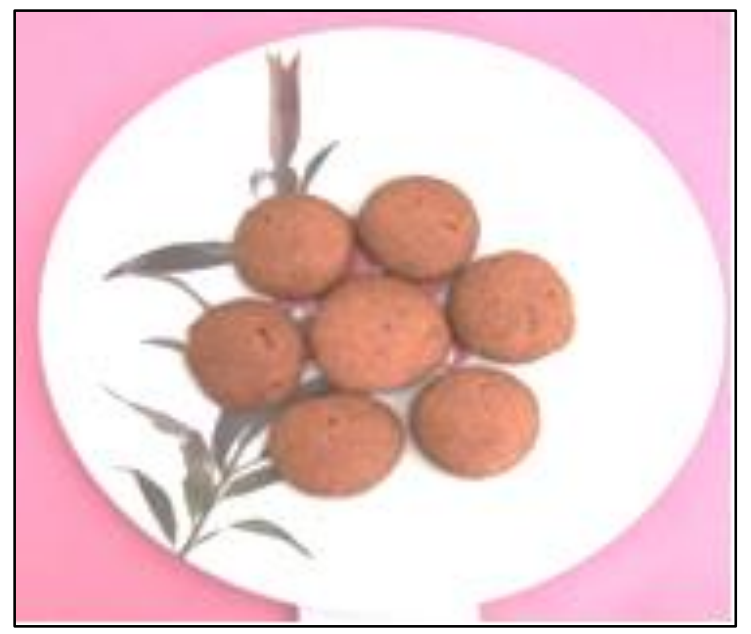

Plate 2(b): Biscuit prepared from GFFM

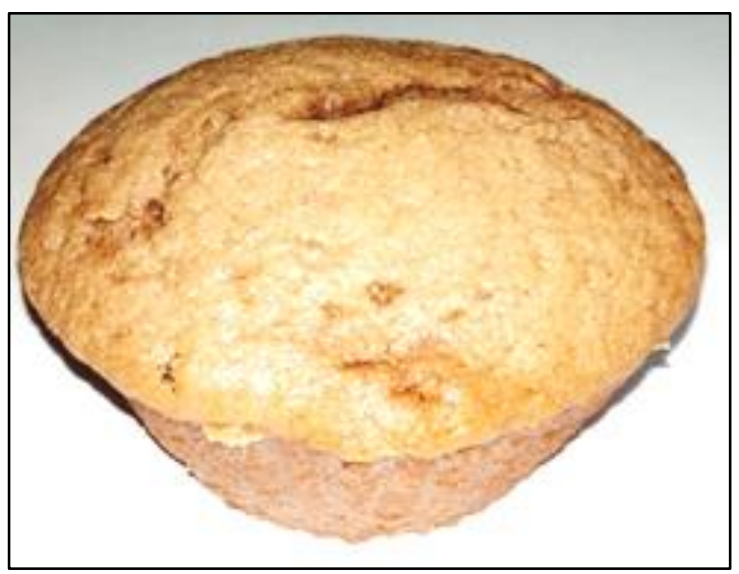

Plate 3(a): Muffin prepared from RWF

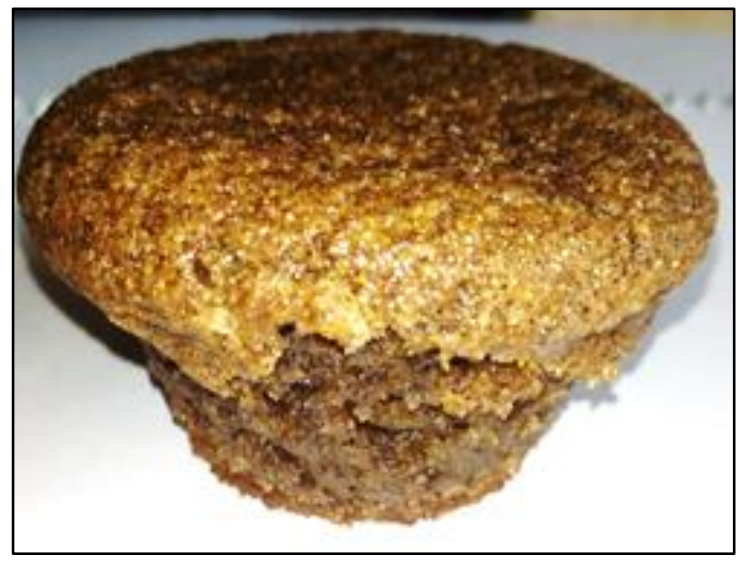

Plate 3(b): Muffin prepared from GFFM

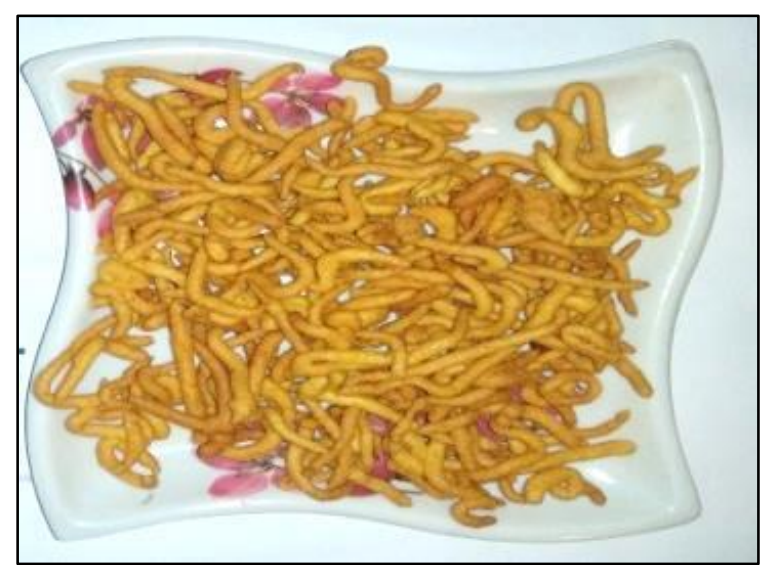

Plate 4(a): Sev prepared from RWF

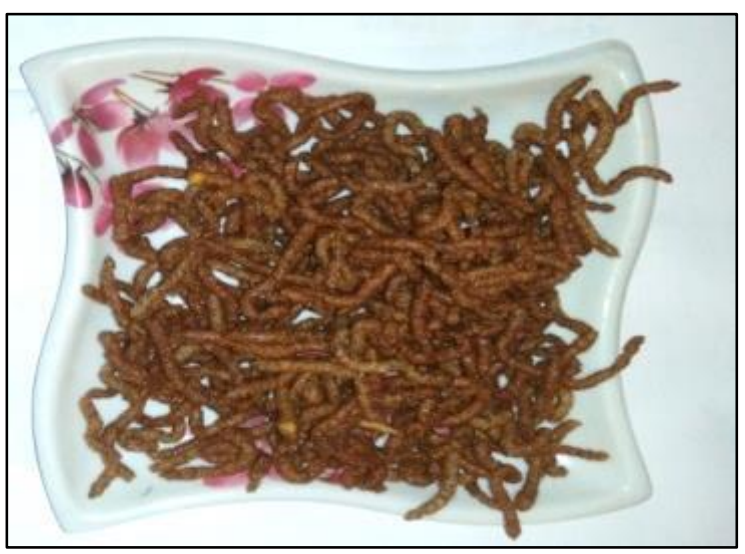

Plate 4(b): Sev prepared from GFFM 


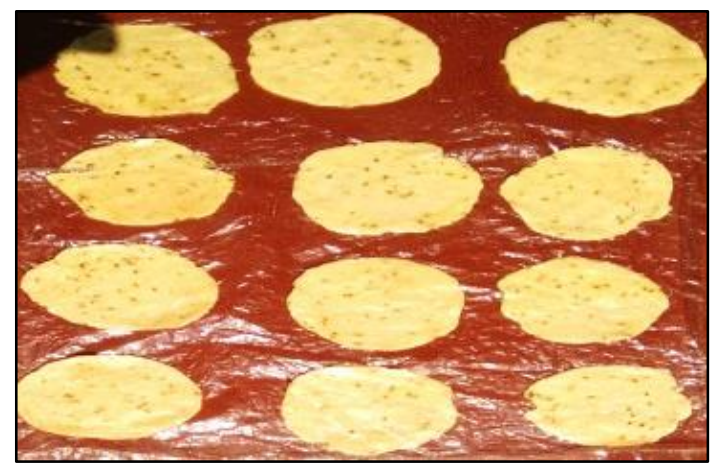

Plate 5(a): Papad prepared from RWF

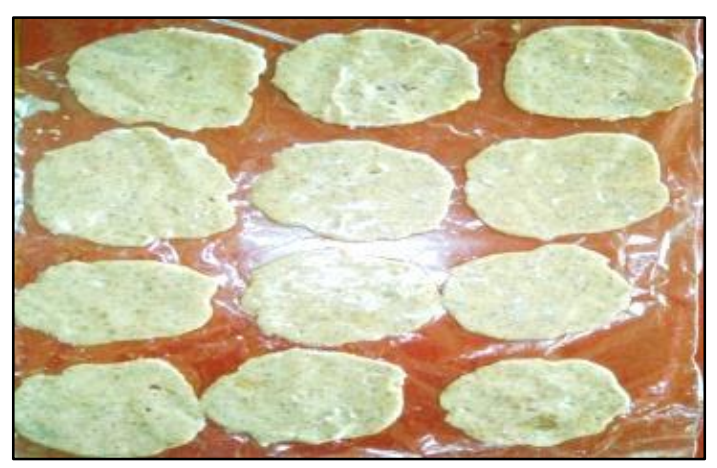

Plate 5(b): Papad prepared from GFFM

\subsection{Organoleptic evaluation of gluten free flour mix recipes}

3.2.1. Namakpara: Table 2 presented data on the acceptability scores of control and GFFM Namakpara. GFFM namakpara was more appreciated as compared to the control. On an overall acceptability basis, GFFM namakpara scored was $8.46 \pm 0.05$ higher as compared to control $8.37 \pm 0.13$ i.e. "Liked very much" by the panel members with regards to all sensory attributes. GFFM namakpara obtained higher score viz., $8.32 \pm 0.18$ for color, $8.45 \pm 0.20$ for flavor, $8.52 \pm 0.25$ for texture, $8.57 \pm 0.13$ for appearance, $8.55 \pm 0.06$ for taste and $8.46 \pm 0.05$ for overall acceptability whereas control namakpara scores viz., $8.25 \pm 0.06$ for color, $8.30 \pm 0.26$ for flavor, $8.45 \pm 0.10$ for texture, $8.55 \pm 0.17$ for appearance, $8.50 \pm 0.12$ for taste and $8.37 \pm 0.13$ for overall acceptability.

Table 2: Mean acceptability scores of GFFM Namakpara

\begin{tabular}{|c|c|c|}
\hline Sensory Parameters & Control & GFFM Namakpara \\
\hline Color & $8.25 \pm 0.06$ & $8.32 \pm 0.18$ \\
\hline Flavor & $8.30 \pm 0.26$ & $8.45 \pm 0.20$ \\
\hline Texture & $8.45 \pm 0.10$ & $8.52 \pm 0.25$ \\
\hline Appearance & $8.55 \pm 0.17$ & $8.57 \pm 0.13$ \\
\hline Taste & $8.50 \pm 0.12$ & $8.55 \pm 0.06$ \\
\hline Overall acceptability & $8.37 \pm 0.13$ & $8.46 \pm 0.05$ \\
\hline
\end{tabular}

3.2.2. Biscuit: It is evident from the result in Table 3 that GFFM biscuit was more appreciated as compared to the control. On an overall acceptability basis, GFFM biscuit 8.58 \pm 0.05 scored was higher as compared to control $8.31 \pm 0.06$ i.e. "Liked very much" by the panel members with regards to all sensory attributes. GFFM biscuit obtained higher score viz., $8.60 \pm 0.09$ for color, $8.40 \pm 0.14$ for flavor, $8.47 \pm 0.13$ for texture, $8.60 \pm 0.10$ for appearance, $8.70 \pm 0.07$ for taste and $8.58 \pm 0.05$ for overall acceptability whereas control biscuit scores viz., $8.25 \pm 0.08$ for color, $8.05 \pm 0.15$ for flavor, 8.30 \pm 0.10 for texture, $8.50 \pm 0.14$ for appearance, $8.62 \pm 0.10$ for taste and $8.31 \pm 0.06$ for overall acceptability.
Table 3: Mean acceptability scores of GFFM Biscuit

\begin{tabular}{|c|c|c|}
\hline Sensory Parameters & Control & GFFM Biscuit \\
\hline Color & $8.25 \pm 0.08$ & $8.60 \pm 0.09$ \\
\hline Flavor & $8.05 \pm 0.15$ & $8.40 \pm 0.14$ \\
\hline Texture & $8.30 \pm 0.10$ & $8.47 \pm 0.13$ \\
\hline Appearance & $8.50 \pm 0.14$ & $8.60 \pm 0.10$ \\
\hline Taste & $8.62 \pm 0.10$ & $8.70 \pm 0.07$ \\
\hline Overall acceptability & $8.31 \pm 0.06$ & $8.58 \pm 0.05$ \\
\hline
\end{tabular}

3.2.3. Muffins: Sensory evaluation of control and GFFM muffins has been presented in Table 4 The overall mean acceptability scores ranged from $8.20 \pm 0.27$ to $8.62 \pm 0.15$ on 9 point hedonic scale. GFFM muffins obtained highest score viz., $8.47 \pm 0.25$ for color, $8.60 \pm 0.10$ for flavor, $8.52 \pm 0.14$ for texture, $8.50 \pm 0.13$ for appearance, $8.39 \pm 0.14$ for taste and $8.62 \pm 0.15$ for overall acceptability whereas control muffins scores viz., $8.42 \pm 0.08$ for color, $8.32 \pm 0.14$ for flavor, $8.20 \pm 0.27$ for texture, $8.42 \pm 0.11$ for appearance, $8.39 \pm 0.08$ for taste and $8.37 \pm 0.09$ for overall acceptability. Hence on the basis of sensory scores it was evident that the GFFM Muffins is the best alternative for Celiac Disease (CD) individual.

Table 4: Mean acceptability scores of GFFM Muffins

\begin{tabular}{|c|c|c|}
\hline Sensory Parameters & Control & GFFM Muffins \\
\hline Color & $8.42 \pm 0.08$ & $8.47 \pm 0.25$ \\
\hline Flavor & $8.32 \pm 0.14$ & $8.60 \pm 0.10$ \\
\hline Texture & $8.20 \pm 0.27$ & $8.52 \pm 0.14$ \\
\hline Appearance & $8.42 \pm 0.11$ & $8.50 \pm 0.13$ \\
\hline Taste & $8.39 \pm 0.08$ & $8.39 \pm 0.14$ \\
\hline Overall acceptability & $8.37 \pm 0.09$ & $8.62 \pm 0.15$ \\
\hline
\end{tabular}

3.2.4. Sev: Table 5 depicted the result of sensory evaluation of control and GFFM sev. GFFM sev was more appreciated as compared to the control. On as overall acceptability basis, GFFM sev $8.65 \pm 0.01$ scored was higher as compared to control $8.46 \pm 0.04$ was "Liked very much" by the panel members with regards to all sensory attributes. GFFM sev obtained high scores viz., $8.62 \pm 0.10$ for color, $8.67 \pm 0.10$ for flavor, $8.67 \pm 0.08$ for texture, $8.47 \pm 0.14$ for appearance, $8.70 \pm 0.10$ for taste and $8.65 \pm 0.01$ for overall acceptability whereas control sev score viz., $8.40 \pm 0.07$ for color, $8.50 \pm 0.08$ for flavor, $8.50 \pm 0.15$ for texture, $8.42 \pm 0.18$ for appearance, $8.67 \pm 0.11$ for taste and $8.46 \pm 0.04$ for overall acceptability.

Table 5: Mean acceptability scores of GFFM Sev

\begin{tabular}{|c|c|c|}
\hline Sensory Parameters & Control & GFFM Sev \\
\hline Color & $8.40 \pm 0.07$ & $8.62 \pm 0.10$ \\
\hline Flavor & $8.50 \pm 0.08$ & $8.67 \pm 0.10$ \\
\hline Texture & $8.50 \pm 0.15$ & $8.67 \pm 0.08$ \\
\hline Appearance & $8.42 \pm 0.18$ & $8.47 \pm 0.14$ \\
\hline Taste & $8.67 \pm 0.11$ & $8.70 \pm 0.10$ \\
\hline Overall acceptability & $8.46 \pm 0.04$ & $8.65 \pm 0.01$ \\
\hline
\end{tabular}

3.2.5. Papad: Table 6 data clearly indicated that scores of the papad ranged between "liked very much" to "like extremely". GFFM papad obtained high scores viz., 8.55 \pm 0.09 for color, $8.45 \pm 0.10$ for flavor, $8.62 \pm 0.13$ for texture, $8.42 \pm 0.08$ for appearance, $8.67 \pm 0.04$ for taste and $8.59 \pm 0.04$ for overall acceptability whereas control papad scores viz., is $8.42 \pm 0.12$ for color, $8.35 \pm 0.06$ for flavor, $8.40 \pm 0.07$ for texture, $8.45 \pm 0.11$ for appearance, $8.40 \pm 0.14$ for taste and $8.39 \pm 0.07$ for overall acceptability. 
Table 6: Mean acceptability scores of GFFM Papad

\begin{tabular}{|c|c|c|}
\hline Sensory Parameters & Control & GFFM Papad \\
\hline Color & $8.42 \pm 0.12$ & $8.55 \pm 0.09$ \\
\hline Flavor & $8.35 \pm 0.06$ & $8.45 \pm 0.10$ \\
\hline Texture & $8.40 \pm 0.07$ & $8.62 \pm 0.13$ \\
\hline Appearance & $8.45 \pm 0.11$ & $8.42 \pm 0.08$ \\
\hline Taste & $8.40 \pm 0.14$ & $8.67 \pm 0.04$ \\
\hline Overall acceptability & $8.39 \pm 0.07$ & $8.59 \pm 0.04$ \\
\hline
\end{tabular}

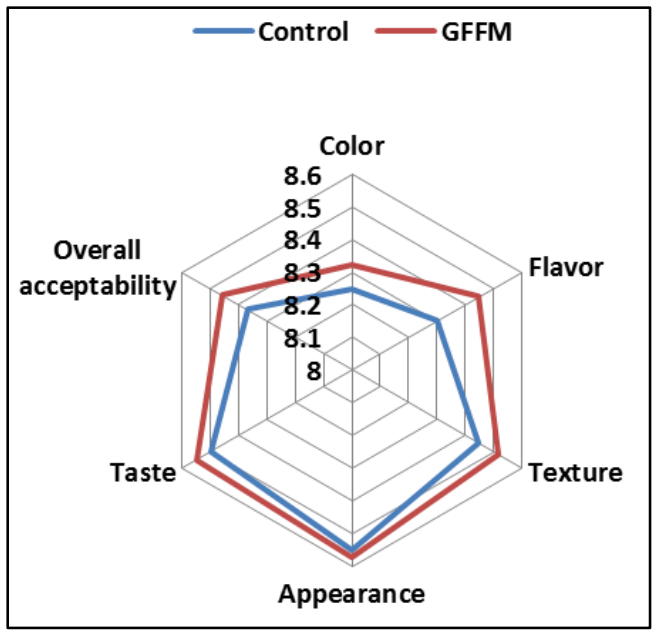

Fig 1: Acceptance Index of Namakpara

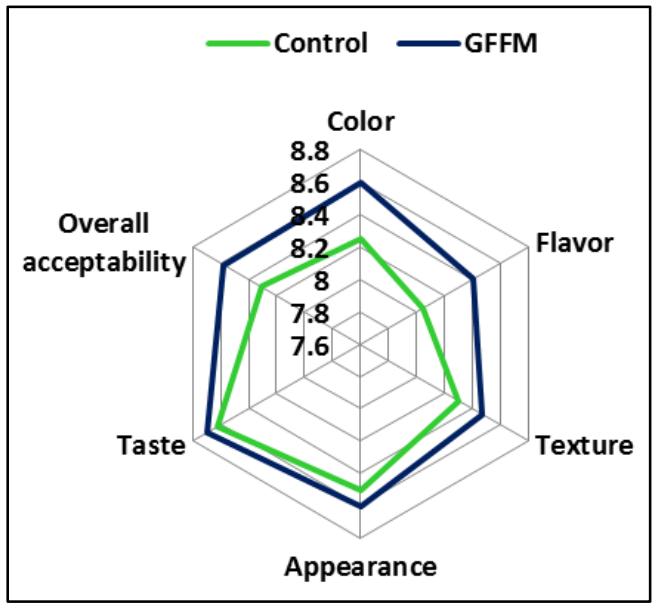

Fig 2: Acceptance Index of Biscuit

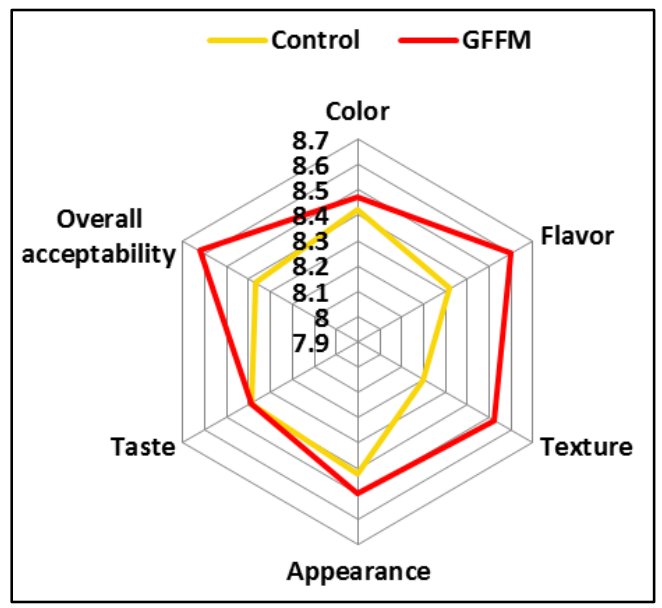

Fig 3: Acceptance Index of Muffins

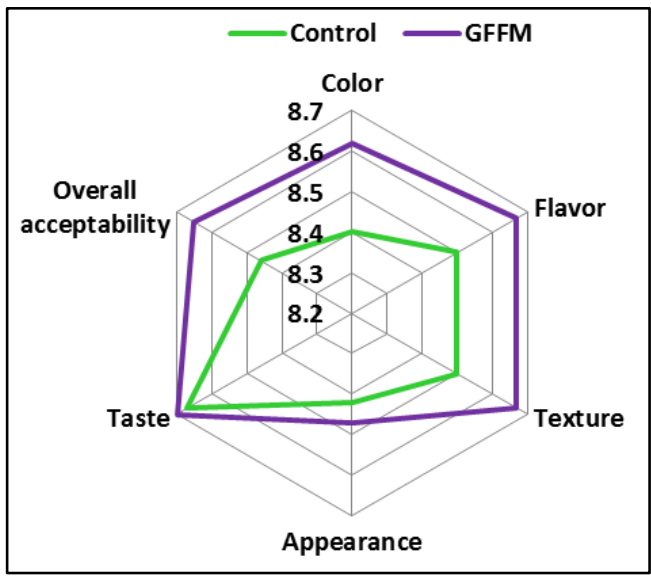

Fig 4: Acceptance Index of Sev

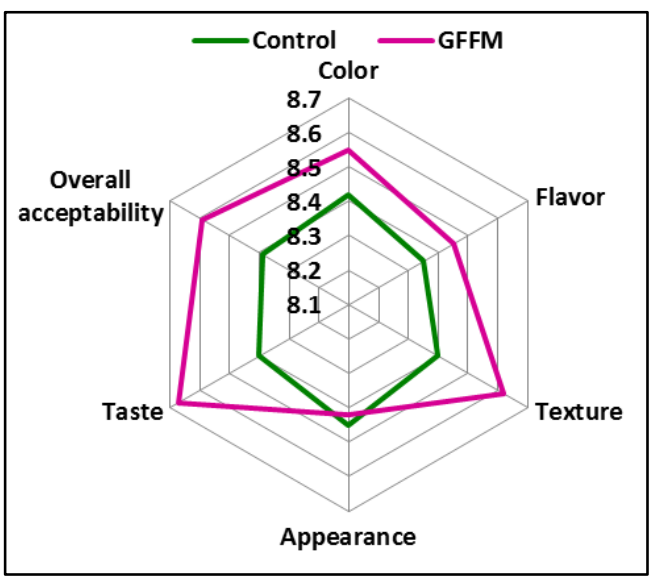

Fig 5: Acceptance Index of Papad

\section{Conclusions}

The products made from Gluten Free Flour Mix were found to be highly acceptable and obtained higher scores as compared to control. Thus on the basis of sensory scores it can be concluded that Gluten Free Flour Mix can be effectively used in developing nutrient rich food products for people suffering from gluten intolerance and low income groups.

\section{References}

1. Alvarez-Jubete L, Arendt EK, Gallagher E. Nutritive value and chemical composition of pseudo cereals as gluten free ingredients. International Journal of Food Science and Nutrition. 2009; 60:240-257.

2. Brown A. Understanding Food Principle and Preparation, Singapore: Thomson Learning Asia 2nd Edition, 2005.

3. Carlos Osella, Maria de La Torre, Hugo Sanchez. Safe Foods for Celiac People. Food and Nutrition science. 2014; 5:787-800.

4. Fasano A Catassi. Clinical Practice Celiac Disease. Nutrition England Journal Medical. 2012; 367:24192426.

5. Feighery C. Celiac Disease. British Medical Journal. 1999; 319:236-239.

6. Goyal V, Sharma MK, Sihag SK, Tomar S, Arora L, Sabikhi AK Singh. Development and physio-chemical characterization of microencapsulated flaxseed oil powder: a functional ingredient for omega-3 fortification. Powder Technology. 2015; 286:527-537.

7. Green P.H. The many faces of celiac disease: Clinical presentation of celiac disease in the adult population. Gastroenterology, 2005; 4:574-8. 
8. Hamer RJ. Coeliac Disease Background and Biochemical Aspect. Biotechnology Advances. 2005; 23:401-408.

9. Krupa-Kozak U, Wronkowska M, Soral-Śmietana M. Effect of buckwheat flour on microelements and proteins contents in gluten-free bread. Czech Journal of Food Science. 2011; 29:103-108.

10. Isabel Comino Maria de, Louders Moreno, Carolina Sousa. Role of oats in celiac disease. World Journal of Gastroenterology. 2015; 21:11825-11831.

11. Letizia Saturni, Gianna Ferretti, Tiziana Bacchetti. The Gluten- Free Diet: Safety and Nutritional Quality. Nutrients. 2010; 2:16-34.

12. Małgorzata Wronkowska, Maria Soral-Śmietana. Buckwheat flour - a valuable component of gluten-free formulations. Polish journal of food and nutrition sciences. 2008; 58:59-63.

13. Segura ME, Rosell CM. Chemical composition and starch digestibility of different gluten free breads. Plant Foods for Human Nutrition. 2011; 66:224-230.

14. Seraphin P Mobarhan. "Mortality in patients with celiac disease". Nutritional Review. 2002; 60:116:118.

15. Srilakshmi. Diet in Gastrointestinal Disease in Dietetics, New Age International Publisher New Delhi. 2014, 287307.

16. Thompson T, Dennis M, Higgins LA, Lee AR, Sharrett MK. Gluten-free diet survey: are Americans with coeliac disease consuming recommended amounts of fibre, iron, calcium and grain foods? Journal of Human Nutrition Diet. 2005; 18:163-169. 